\title{
17. On a New Species of a Luminous Squid from the Sea of Japan.
}

By Masashi IsHIKAWA.
Fishery Department, Faculty of Agriculture, Tokyo Imperial University.

(Comm. by C. Ishikawa, M.I.A., Jan. 12, 1929.)

Abralia japonica n. sp.

The animal small and loliginiform ; the mantle cylindrical in front; tapering gradually to a blunt point posteriorly; its greatest breadth about one-third as long as the mantle. The anterior mantle-margin slightly projected to form an obtuse median point above and laterally a $\wedge$-shaped one on either side of the funnel. The fins large, broadly sagittate; the anterior margin of each fin arcuate, descending abruptly inward from a nearly right angle anteriorly ; the angles of the lateral margins rounded; the hinder margin slightly concave, projected posteriorly to an acute point, their total width at the point of the greatest expansion a little longer than the length and 73 per cent of the mantlelength.

The head large, somewhat flattened, excavated beneath; the neck as usual with a distinct boundry crest of the olfactory organ on each side. The buccal membrane well developed, eight pointed; its inner surface covered with papillae of considerable size. The eyes large, rounded; the ocular apertures large, with a distinct sinus in front. The funnel compressed, a little projected. Each funnel-locking cartilage a large elongate, ovate plate, deeply excavated down the centre, its groove corresponding with a simple linear ridge on the inner surface of the mantle.

The arms nearly equal ; the longest ventral arm 44 per cent of the dorsal mantle-length. The first and second pair of arms has a low colorless membraneous keel along the outer margin of the entire length, except at the extreme base; along the ventral margin of the area bearing the hooks and suckers is a delicate protecting membrane supported by a series of fleshy lappets. The outer membraneous colorless keel of the third arm very broad, and exceeds the diameter of the arm itself at the widest point below the middle of the arm; the ventral margin also furnished with a protecting membrane. The ventral arm longest, and more gradually tapering than the other arms; devoid of protecting membranes, but with a well developed keel along the outer 
angle. All these arms bear small stout hooks in two alternating rows, replaced by some two series of suckers at the extremity, except on the tip of the ventral arm.

In the following table the numbers of hooks and suckers are given :

Sp. No. 101

\begin{tabular}{|c|c|c|c|c|c|c|c|}
\hline I & II & III & IV & I & II & III & IV \\
\hline .... 12 & 12 & 14 & 8 & 12 & 12 & 14 & 8 \\
\hline$\ldots 14$ & 11 & $3 ?$ & 0 & 12 & $8 ?$ & $4 ?$ & 0 \\
\hline
\end{tabular}

The horny ring of the suckers armed with rather elongated teeth along the distal side; about seven teeth in number can be counted.

As all the specimens I have seen are females, the hectocotylized arm and the other sexual characters have not been observed.

The tentacles slender, about the length of the mantle; the inner surface of the stalk flattened, unadorned with chromatophores. The club small or not at all expanded; the web of the outer margin small ; along the proximal ventral edge of the internal surface are two very large elongated, strongly incurved, sharply pointed hooks projecting for some distance from their large fleshy bases; opposite these along the dorsal margin a single series of minute, short pedicelled suckers, usually three in number; beyond the hooks, the distal two-third furnished with four crowded rows of minute suckers, regularly diminishing in size toward the tip. The fixing apparatus well developed near the base of the club, and comprises three small short-stalked suckers, alternating with five minute pads. The horny ring of the tentacular suckers entire.

The gladius lanceolate with broad wings; embracing the strong median ridge visible through the dorsal integument as a purplish dark median line.

Numerous minute luminous organs, appearing as dark bluish dots having a paler opaque lens in the centre, distributed over the ventral surface of the mantle, head, funnel, ventral and third arms. These luminous dots are evenly scattered over the ventral surface of the mantle and the funnel ; on the head there is a distinct circlet of the organs surrounding the ocular aperture; between these about ten rows are scattered, but the exact number of the rows is difficult to determine ; the ventral arms have two rows and the third arms have a single row of about 8 organs along the base of the outer keel.

On the ventral periphery of the eye-ball, there is a distinct special type of the luminous organ in a single series of five circular bodies, brownish orange in color ; the two terminal ones are somewhat larger 
than the central which is equal in size. These argans are usually visible through the outer integument which normally covers the eye-ball.

The color in formalin pale yellowish brown, dotted over nearly the entire surface with small dark purple-brown chromatophores, most numerous on the upper surface of the head where they are especially visible in a form of a single large chromatophore surrounded by a circlet of smaller ones. On the ventral surface of the fins, the inner surface and the outer keels of the arms, the integument entirely free from the chromatophres. The buccal membrane deep violet.

The measurements of a well-preserved female are given below :

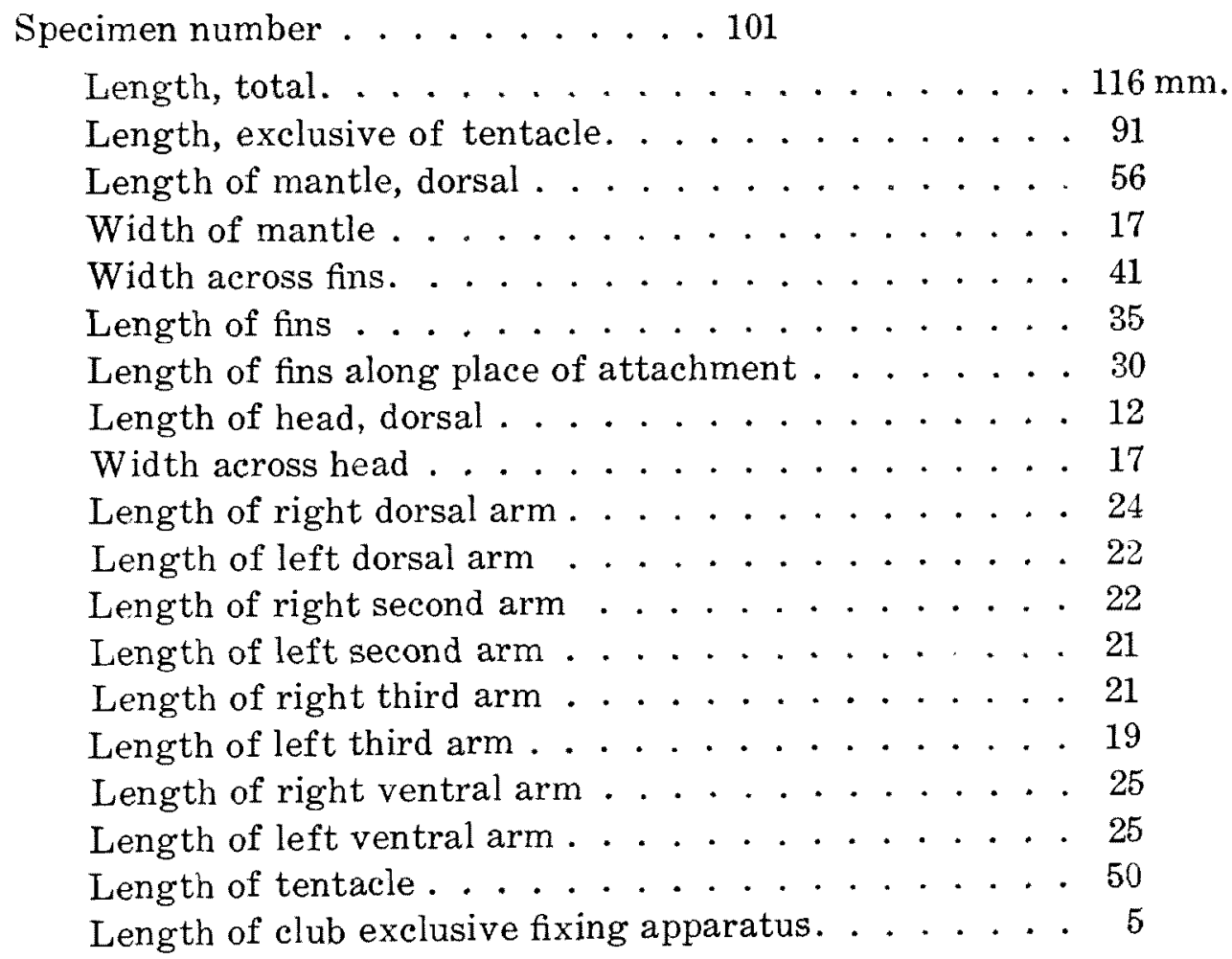

Type.-No. 101. Fishery Department, Faculty of Agriculture, Tokyo Imperial University ; a mature female.

Type locality. - Bay of Toyama, Japan Sea.

Materials examined. - A female specimen (No. 101) taken in the Toyama bay by T. Kishitani, another female (No. 102) in the same bay by Y. Yasaki have been examined.

Remarks. - Judging from these two specimens at hand, of which the one is not in the best state of preservation, this beautiful squid approaches very closely to Abralia andamanica Goodrich, but differs from it in (1) the more bulky outline of the body, (2) the less number of hooks and suckers on the arms, (3) the less number of the hooks on the tentacular clubs, and (4) the form of the luminous organs on the eyeballs. 
Another more allied form appears to be Watasenia scintillans (Berry) with a distinct peculiar group of the luminous organ on the tip of the ventral arms, which is not to be recognized in both the present specimens, as above stated. Moreover, as it seems that this absence of the organ is neither to be looked upon as the result of an accident nor as due to a secondary or ontogenetic circumstance, this species may be ascribed as new to science.

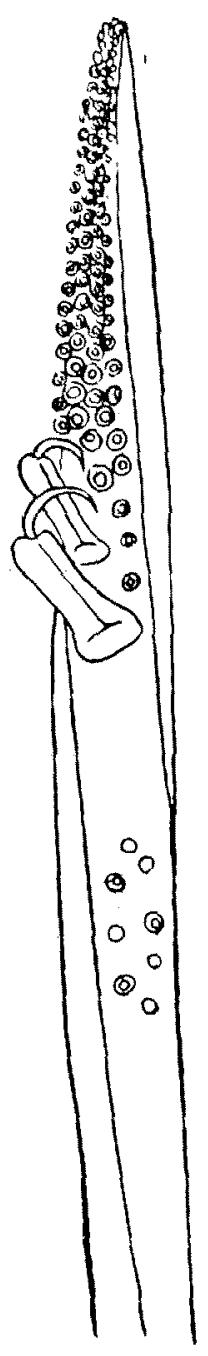

$a$

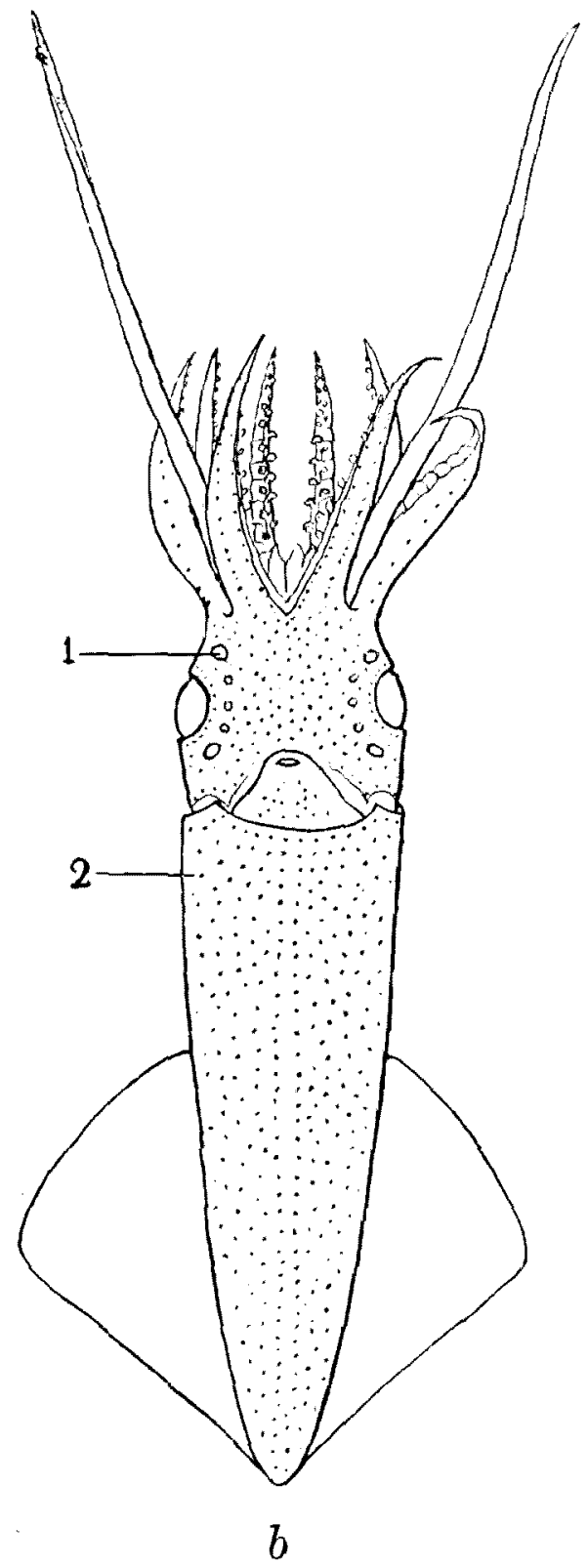

Fig. 1. Abralia japonica n. sp.

a. Tentacular club, $\times 10$.

$b$. Ventral view of type, natural size.

1. Luminous organs on ey eball seen through integment.

2. Luminous dots. 